\title{
PAIN RELIEF WITH PREVENTIVE MEASURES AMONG KNEE OSTEOARTHRITIS PATIENTS: A COMPARISON BETWEEN FOLLOWERS VERSUS NON FOLLOWERS
}

\author{
Muhammad Ikram, Sadia Ijaz, Munawer Latif Memon, Varda Balouch, Sajid Ejaz Rao \\ Pakistan Ordinance Factory (POF) Hospital, Wah Cantt/National University of Medical Sciences (NUMS) Pakistan
}

\begin{abstract}
Objective: To compare mean pain scores among knee osteoarthritis patients following or not following preventive measures.

Study Design: Comparative prospective study.

Place and Duration of Study: The study was conducted at the department of orthopedics, Pakistan Ordinance Factory (POF) Hospital, Wah Cantt, from Jun 2018 to May 2019.

Methodology: Patients were divided into two groups (using random number table); group A was given pain relief medications only while group B was given a combination of pain relief medication and preventive measure. Patients were followed for 3 and 6 months after the intervention. Data was analyzed with SPSS software.

Results: Total 52 knee osteoarthritis patients were included in study (26 patients in each group). Mean age of patients was $54.3 \pm 6.4$ year. Significantly lower pain scores were found in group B as compared to group A after 3 (5.50 \pm 0.98 vs $4.84 \pm 1.00$ respectively, $p=0.02)$ and 6 months ( $3.53 \pm 0.50$ vs $4.96 \pm 1.11$ respectively, $p<0.01)$ of intervention. Knee injury and osteoarthritis outcome scores were significantly lower in group B as compared to group A $(p<0.05)$ after 6 months.

Conclusion: Pain is most common knee osteoarthritis symptom. Combination of pain relief medicines and preventive measures in daily life are more effective in controlling pain intensity as compared to pain relief medications only. Early diagnosis and management can improve disease prognosis.
\end{abstract}

Keywords: Knee osteoarthritis, Pain, Preventive measures.

This is an Open Access article distributed under the terms of the Creative Commons Attribution License (http://creativecommons.org/licenses/by/4.0), which permits unrestricted use, distribution, and reproduction in any medium, provided the original work is properly cited.

\section{INTRODUCTION}

Knee Osteoarthritis (OA) is common form of degenerative joint disease leading towards significant disability ${ }^{1}$. Knee osteoarthritis affects 250 million people, worldwide ${ }^{2}$. Prevalence of knee osteoarthritis is $33.6 \%$ in United States (affecting majority of patients in age above 65 years $)^{3}$. Prevalence of knee osteoarthritis in Pakistan is $28 \%$ among urban residing population ${ }^{4}$. High prevalence of knee osteoar-thritis is associated with strenuous physical activity (knee bending, prolonged standing, kneeling and squatting) and knee injury/trauma 5 .

Evidence exists that knee is composed of three major compartment (medial tibiofemoral, lateral tibiofemoral and patellofemoral joint). These compartments are involved in modified

Correspondence: Dr Muhammad Ikram, Department of Orthopedics, POF Hospital, Wah Cantt Pakistan

Received: 30 Mar 2020; revised received: 02 Jul 2020; accepted: 07 Jul 2020 hinge joint formulation allowing knee to straighten, bend and rotate (side to side). Functional capacity of knee joint is affected by excessive weight on knee 6 . Knee osteoarthritis is divide into two main categories on the basis of diseases etiology. These categories include primary knee osteoarthritis (idiopathic/non traumatic) and secondary knee osteoarthritis (due to mechanical misalignment, injury or trauma). Kellgren-Lawrence $(\mathrm{KL})$ system is a radiological system of findings used for diseases severity grading since 19577.

Symptoms of knee OA depends upon its causes. The most common symptom is pain. This pain could be sharp, consistent, dull or off and on. Severity of pain ranges from mild to agonizing. Pain onset could be sudden or develop slowly and worsen with passage of time. During rest or at night pain symptoms could be more frequent, however, pain might be flare up with excessive work or activity. Other symptoms of KOA 
include reduction in range of motion, muscle weakness, locking, popping sounds, and swelling of knee joint ${ }^{8}$.

Management of knee osteoarthritis includes non surgical and surgical management. Non surgical management involves heat and cold treatment for pain relief. Preventive measures to avoid pain stimulus trigger. Weight loss procedure, electrical stimulation, use of assistive devices, medications (Non steroid anti inflammatory drugs) and intr-articular knee injections are also part of non surgical treatment. Therapeutic exercises are recommended as first line treatment option in non surgical management. Low impact aerobic exercise, strengthening, physical activity for symptomatic knee osteoarthritis and neuromuscular education are strongly recommended by American Academy of orthopedic surgeons guidelines ${ }^{9}$. Sparkes et al reported that knee pain scores were $54.18 \pm 12.78 \mathrm{SD}$ in cases and $95.57 \pm 11.7 \mathrm{SD}$ in control group after intervention $(p<0.05)^{10}$. Knee osteoarthritis is an emerging painful issue affecting majority of old age population in Pakistan. Limited data is available on efficacy of preventive measures regarding knee osteoarthritis. Present study was planned to compare mean pain scores among knee osteoarthritis patients following or not following preventive measures.

\section{METHODOLOGY}

A comparative prospective study was conducted at department of orthopedics, Pakistan Ordinance Factory (POF) hospital, Wah Cantt. Study duration was one years (June 2018 to May 2019). A sample size of 52 patients was calculated (1:1 randomization 26 patients in each group) with $\mu 1=4.46, \mu 2=3.48$, Standard deviation $=1.389$, Power of study $=80 \%$, Confidence interval 95\% using WHO calculator ${ }^{11}$. Knee OA patient were selected through non probability consecutive sampling. Ethical approval was taken from ethics review board of POF Hospital (IRB no=3477). Consent forms were signed by all participating patients. Inclusion criteria was based upon age 45-70 years, both genders, patients diagnosed with knee osteoarthritis on the basis of kellgren Lawrence grading system ( 3 and 4 grade), disease duration at least 6 months, patients with both unilateral and bilateral (medial or lateral) KOA, primary knee osteoarthritis, no history of soft tissue injury in lower limb or lower extremity joint surgery and pain intensity ranging $\geq 4$ to 10 on visual analogue scale (ranging from no pain to extreme pain), neurological or balance disorders, history of head injury or cerebrovascular accident, smokers, alcohol or substance abusers and patients with systemic inflammatory arthritis were excluded from study. Patients were randomly divided into two groups using computer generated random number table. Group A was given medications for pain relief (Paracetamol tablet $325 \mathrm{mg}$ in breakfast and combination of paracetamol tablet (325 mg) plus Tramadol tablet (37.5mg) at night). Group B was given pain relief medication and patients were instructed to follow preventive measures (use chair for namaz, commode for washroom, avoid squatting/low sitting, avoid stairs/long duration of standing/brisk walk and use of walking sticks). Patients were followed for 3 and 6 months after intervention. A combination of visual analogue scale, knee injury and Osteoarthritis outcome score (KOOS) was used for evaluation of primary endpoints mean pain scores before and after intervention, mean symptoms scores and scores of daily living activities in both groups (KOOS scores were converted into percentage score $0=$ extreme knee problems to $100=$ no knee problem) ${ }^{15}$. Data was analyzed using SPSS version 24. Mean and standard deviation was calculated for numerical data, however, frequencies and percentages were calculated for categorical data. Stratification was done for controlling effect modifiers like age, gender and duration of disease. Post stratification $\mathrm{T}$ test was applied. A $p$-value less than or equal to 0.05 was considered significant in our study.

\section{RESULTS}

Total 52 knee OA patients were included in study (26 patients in each group). There were 21 $(40.4 \%)$ male and 31 (59.6\%) female in our study. Mean age of patients was $54.3 \pm 6.4$ years. There 
were $28(53.8 \%)$ patients in age group $45-55$ years and $24(46.2 \%)$ in age group 56-70 years. Mean weight of patients $86.4 \pm 4.5 \mathrm{~kg}$ and mean body mass index (BMI) of patients was $29.1 \pm 1.7 \mathrm{~kg} /$

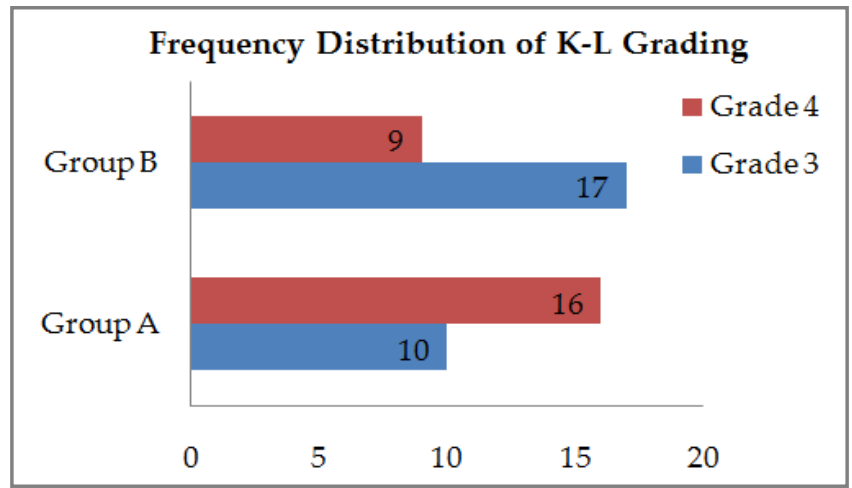

Figure: Frequency distribution of patients according to $\mathrm{K}-\mathrm{L}$ grading evidence.

$\mathrm{m}^{2}$. Majority of patients in group A fall $\mathrm{n}$ grade 4 category of KL grading system while in group B majority of patients fall in grade 3 category $(30.8 \%$ vs $32.7 \%)$ a shown figure. Mean pain medication (group A) only after 6 months (3.53 \pm 0.50 vs $4.96 \pm 1.11, p<0.001)$ as shown in table-I. Pain scores were significantly high in older age group (46-70 years) as compared to younger middle age group (45-55 years) $(p=0.02)$. Gender has insignificant impact on pain scores $(p=0.452)$.

Significantly high pain, symptoms and daily living activities scores indicate low pain, less symptoms and better living activities in group B patients as compared to group A according to KOOS outcomes after 6 months $(p<0.001, p<0.01$ and $p=0.001$ respectively) as shown in table-II. However, no significant difference was found in KOOS outcomes after 3 months (pain scores $p=$ 0.521 , symptoms score $p=0.410$, daily living scores $p=0.77)$.

\section{DISCUSSION}

Knee osteoarthritis is a common degenerative joint disorder with significant impact on Pakistan Health care system. Management of

Table-I: Comparison of pain scores in both interventional groups.

\begin{tabular}{|c|c|c|c|c|}
\hline $\begin{array}{l}\text { Pain Scores } \\
\text { according to VAS }\end{array}$ & Interventional Groups & $\mathrm{n}=52$ & Mean \pm SD & $p$-value \\
\hline \multirow{2}{*}{ Before treatment } & Group A (Medications only) & 26 & $6.38 \pm 0.4 \mathrm{SD}$ & \multirow{2}{*}{$<0.001$} \\
\hline & Group B (Medication plus preventive measures & 26 & $5.92 \pm 0.9 \mathrm{SD}$ & \\
\hline \multirow{2}{*}{ After 3 months } & Group A (Medications only) & 26 & $5.50 \pm 0.98 \mathrm{SD}$ & \multirow{2}{*}{0.0013} \\
\hline & Group B (Medication plus preventive measures & 26 & $4.84 \pm 1.0 \mathrm{SD}$ & \\
\hline \multirow{2}{*}{ After 6 months } & Group A (Medications only) & 26 & $4.96 \pm 1.11 \mathrm{SD}$ & \multirow{2}{*}{$<0.001$} \\
\hline & Group B (Medication plus preventive measures & 26 & $3.53 \pm 0.50$ & \\
\hline \multicolumn{5}{|c|}{ Table-II: Comparison of KOOS outcomes in both interventional groups. } \\
\hline $\begin{array}{l}\text { KOOS Outcomes } \\
\text { After } 6 \text { Months }\end{array}$ & Interventional Groups & $\mathrm{n}=52$ & Mean \pm SD & $p$-value \\
\hline \multirow{2}{*}{ Pain scores } & Group A (Medications only) & 26 & $52.6 \pm 7.7 \mathrm{SD}$ & \multirow{2}{*}{$<0.001$} \\
\hline & Group B (Medication plus preventive measures & 26 & $70.6 \pm 5.1 \mathrm{SD}$ & \\
\hline \multirow{2}{*}{ Symptoms Scores } & Group A (Medications only) & 26 & $44.8 \pm 3.8 \mathrm{SD}$ & \multirow{2}{*}{$<0.01$} \\
\hline & Group B (Medication plus preventive measures & 26 & $66.7 \pm 3.4$ & \\
\hline \multirow{2}{*}{$\begin{array}{l}\text { Daily living } \\
\text { activities scores }\end{array}$} & Group A (Medications only) & 26 & $43.0 \pm 2.4 \mathrm{SD}$ & \multirow{2}{*}{0.001} \\
\hline & Group B (Medication plus preventive measures & 26 & $55.8 \pm 3.9 \mathrm{SD}$ & \\
\hline
\end{tabular}

scores before treatment in group A were $6.38 \pm$ 0.4 and in group B were $5.92 \pm 0.9(p<0.001)$. However, Low pain scores were found in group B as compared to group A after treatment (4.84 \pm 1.00 vs $5.50 \pm 0.98$ respectively, $p=0.0013$ ) after 3 months. Combination of pain relief medicines and preventive measures (group B) leads to lower pain scores as compared to pain relief knee OA involves painful signals control, improvement in quality of life and knee functionality ${ }^{12}$. Moreover, aquatic exercises, resistance land based exercises or aerobic exercises are recommended for Knee OA American College of Rheumatology ${ }^{11}$. Osteoarthritis Research Society International advocate strengthening, range of motion and regular exercises are important therapeutic 
pain relieving exercises for knee $\mathrm{OA}^{13}$. Surgical treatment involved arthroscopy, knee replacement, osteotomies and cartilage repair ${ }^{14}$.

In present study, pain scores were significantly lower among patients following combination of medication and preventive measure as compared to those who were on medications only $(p<0.001)$. Yildrim et al reported that visual analogue scores (VAS) of pain in therapeutic group were $4.46 \pm 1.775 \mathrm{SD}$ and control group was 3.48 $\pm 1.389 \mathrm{SD}$ among knee osteoarthritis patients ${ }^{15}$ Hunt et al reported that acetaminophen is an effective pain control drug for management of knee OA with minimum to moderate pain as compared to controls ${ }^{16}$. However, Allen et al reported that NSAIDs are superior to acetaminophen in pain control among Knee OA patients ${ }^{17}$. Dhumke et al reported that tramadol is a common drug used against neuropathic pain. They reported $50 \%$ pain relief efficacy with limited complications ${ }^{18}$. According to american pain society tramadol could be used as pain relieving drug in combination with parcetamol/NSAIDS among knee OA patients ${ }^{19}$. According to American College of Rheumatology, tramadol is effective as an adjunctive therapy and showed comparable results to ibuprofen in knee OA patients ${ }^{20}$.

In present study, use chair for namaz, commode for washroom, avoid squatting/low sitting, avoid stairs/long duration of standing/brisk walk and use of walking sticks plus combination of pain relief medication is found to be effective in controlling pain following KOOS pain scores as compared to medications group only $(p<0.001)$. Brouwer et al reported that knee alignment (static and dynamic) is an effective prevention for pain by load distribution within knee ${ }^{21}$. Zhang et al reported that prevention of obesity is directly associated with pain reduction in KL grade 3 and 4 of knee $\mathrm{OA}^{22}$. Aweid et al reported that prevention of vitamin $\mathrm{D}$ deficiency can limit pain severity during knee $\mathrm{OA}^{23}$.

In present study, a significantly low symptoms and daily living activities in group $B$ as compared to group A $(p<0.01$ and $p=0.001$ respec- tively). Sparkes et al reported that mean pain scores, symptoms and daily living activities in osteoarthritis group was $54.18 \pm 12.77 \mathrm{SD}, 52.85 \pm$ 18.34 and $63.40 \pm 18.05 S D$ respectively as compared to controls $(p<0.005)$ with KOOS outcomes scale. This study reported significantly high KOOS scores in control group indication high pain and symptoms in cases as compared to controls $^{15}$. Another similar study reported that patients with moderate osteoarthritis were able to control pain and complete daily life activities with preventive measures as compared to controls ${ }^{24}$. Kisand et al reported that appropriate lubrication, proper nutrition is effective in maintaining muscle strength and knee stability. Protective measures and effective analgesics can improve patient's quality of life and restore functional ability ${ }^{25}$.

\section{LIMITATION OF STUDY}

Small sample size and conduction of study at single hospital and patients who were using preventive measures as part of their life style (like comord for washroom and chair for namaz) over predict results in medications only group, thus limiting generlisability of study.

\section{CONCLUSION}

Pain is most common knee osteoarthritis symptom. Combination of pain relief medicines and preventive measures in daily life are more effective in controlling pain intensity as compared to pain relief medications only. Early diagnosis and management can improve disease prognosis.

\section{CONFLICT OF INTEREST}

This study has no conflict of interest to be declared by any author.

\section{REFERENCES}

1. Robinson $W H$, Lepus $C M$, Wang $Q$, Raghu $H$, Mao R, Lindstrom $\mathrm{TM}$, et al. Low-grade inflammation as a key mediator of the pathogenesis of osteoarthritis. Nat Rev Rheumatol 2016; 12(10): 580-92.

2. Dulay GS, Cooper C, Dennison EM. Knee pain, knee injury, knee osteoarthritis \& work. Best Pract Res Clin Rheumatol 2017; 29(3): 454-61.

3. Magnusson K, Turkiewicz A, Englund M. Nature vs nurture in knee osteoarthritis - the importance of age, sex and body mass index. Osteoarthr Cartil 2019; 27(4): 586-92. 
4. Iqbal NM, Haidri RF, Motiani B, Mannan A. Frequency of factors associated with knee osteoarthritis. J Pak Med Assoc 2011; 61(8): 786-89.

5. Manlapaz DG, Sole G, Jayakaran P, Chapple CM. Risk factors for falls in adults with knee osteoarthritis: A systematic review. PM R 2019; 11(7): 745-57.

6. Manlapaz DG, Sole G, Jayakaran P, Chapple CM. Risk factors for falls in adults with knee osteoarthritis: A systematic review. PM R 2019; 11(7): 745-57.

7. Li JS, Tsai TY, Clancy MM, Li G, Lewis CL, Felson DT. Weight loss changed gait kinematics in individuals with obesity and knee pain. Gait Posture 2019; 68(1): 461-65.

8. Collins NJ, Hart HF, Mills KAG. Osteoarthritis year in review 2018: rehabilitation and outcomes. Osteoarthr Cartil 2019; 27(3): 378-91.

9. Afzali T, Fangel MV, Vestergaard AS, Rathleff MS, Ehlers LH, Jensen MB. Cost-effectiveness of treatments for non-osteoarthritic knee pain conditions: A systematic review. PLoS ONE 2018; 13(12): 0209240.

10. Sparkes V, Whatling MG, Biggs P, Khatib N. Comparison of gait, functional activities, and patient-reported outcome measures in patients with knee osteoarthritis and healthy adults using 3D motion analysis and activity monitoring: an exploratory casecontrol analysis. Orthop Res Rev 2019; 11(1): 129-40.

11. Alshami MA. Knee osteoarthritis related pain: a narrative review of diagnosis and treatment. Int J Health Sci (Qassim) 2014; 8(1): 85-104.

12. Hochberg MC, Altman RD, April KT, Benkhalti M, Guyatt G, McGowan J. American College of Rheumatology 2012 recommendations for the use of nonpharmacologic and pharmacologic therapies in osteoarthritis of the hand, hip, and knee. Arthritis Care Res (Hoboken) 2012; 64(4): 465-74.

13. Alrushud AS, Rushton AB, Bhogal G, Pressdee F. Effect of a combined programme of dietary restriction and physical activity on the physical function and body composition of obese middleaged and older adults with knee OA (DRPA): protocol for a feasibility study. Bio Med J Open 2018; 8(12): 021051.

14. Martel-Pelletier J, Maheu E, Pelletier JP, Alekseeva L, Mkinsi O, Branco J, et al. A new decision tree for diagnosis of osteoarthritis in primary care: international consensus of experts. Aging Clin Exp Res 2019; 31(1): 19-30.
15. Yıldırım MA, Uçar D, Öneş K. Comparison of therapeutic duration of therapeutic ultrasound in patients with knee osteoarthritis. J Phys Ther Sci 2015; 27(12): 3667-70.

16. Hunt MA, Wrigley TV, Hinman RS, Bennell KL. Individuals with severe knee osteoarthritis (OA) exhibit altered proximal walking mechanics compared with individuals with less severe $\mathrm{OA}$ and those without knee pain. Arthritis Care Res (Hoboken) 2010; 62(10): 1426-32.

17. Allen KD, Coffman CJ, Golightly YM, Stechuchak KM, Voils CI, Keefe FJ. Comparison of pain measures among patients with osteoarthritis. J Pain 2010; 11(6): 522-27.

18. Duhmke RM, Cornblath DD, Hollingshead JR. Tramadol for neuropathic pain. Cochrane Database Syst Rev 2004; 1(2): CD003726.

19. Park KS, Choi JJ, Kim WU, Min JK, Park SH, Cho CS. The efficacy of tramadol/acetaminophen combination tablets (Ultracet $\left.{ }^{\circledR}\right)$ as add-on and maintenance therapy in knee osteoarthritis pain inadequately controlled by nonsteroidal anti-inflammatory drug (NSAID). Clin Rheumatol 2012; 31(2): 317-23.

20. Babul N, Noveck R, Chipman H, Roth SH, Gana T, Albert K. Efficacy and safety of extended-release, once-daily tramadol in chronic pain: a randomized 12-week clinical trial in osteoarthritis of the knee. J Pain Symptom Manage 2004; 28(1): 59-71.

21. Brouwer GM, van Tol AW, Bergink AP, Belo JN, Bernsen RM, Reijman $\mathrm{M}$, et al. Association between valgus and varus alignment and the development and progression of radiographic osteoarthritis of the knee. Arthritis Rheum 2007; 56(4): 1204-11.

22. Zhang Y, Niu J, Felson DT, Choi HK, Nevitt M, Neogi T. Methodologic challenges in studying risk factors for progression of knee osteoarthritis. Arthritis Care Res (Hoboken) 2010; 62(11): 1527-32.

23. Aweid O, Haider Z, Saed A, Kalairajah Y. Treatment modalities for hip and knee osteoarthritis: A systematic review of safety. J Orthop Surg (Hong Kong) 2018; 26(3): 2309499018808669.

24. Neogi T, Zhang Y. Osteoarthritis prevention. Curr Opin Rheumatol 2011; 23(2): 185-91.

25. Kisand K, Tamm AE, Lintrop M, Tamm AO. New insights into the natural course of knee osteoarthritis: early regulation of cytokines and growth factors, with emphasis on sex-dependent angiogenesis and tissue remodeling. A pilot study. Osteoarthr Cartil 2018; 26(8): 1045-54. 